\title{
Realization of mechanical decoupling zones for package-stress reduction
}

\author{
V L Spiering, S Bouwstra and J H J Fluitman \\ MESA Research Institute, University of Twente, P O Box 217, 7500 AE Enschede (Netherlands)
}

\begin{abstract}
The realization of mechanical decouping zones around a membrane to reduce package stresses is presented Wet-1sotropic etching with a nitric/luondic solution $\left(\mathrm{HNO}_{3} / \mathrm{HF} / \mathrm{H}_{2} \mathrm{O}\right)$ as well as reactive-1on etching (RIE) with a sulphurhexafluonde/oxygen $\left(\mathrm{SF}_{6} / \mathrm{O}_{2}\right)$ plasma are investigated to realize deep crrcular grooves The shape of the cross section of the groove, which determines the shape of the decoupling zone, can be controlled using the RIE method by changing the etch conditions It is shown that a large undercut at low pressures as well as a small undercut at high pressures is possible with a $\mathrm{SF}_{6} / \mathrm{O}_{2}$ plasma, leading to round or steep sidewalls of the grooves, respectively Finally a completed bare structure containing a membrane and a surrounding decoupling zone is presented
\end{abstract}

\section{Introduction}

Many solid-state devices deal with the problem of packaging Unwanted stresses like encapsulation stresses and thermally-induced stresses during operation affect the device characteristics Especially in micromechanical sensors with a large sensitivity to mechanical stresses the output signal can be disturbed [1] These package stresses can be reduced by means of a mechanical decoupling zone $[2,3]$ In general application of the zone is useful for transversely-loaded micromechanical devices, e g, pressure sensors In ref 2 a theoretical model has been presented for the mechanical behaviour of a thin circular zone with a V-shaped cross section The application for an on-chip decoupling zone around the membrane of a pressure sensor, see Flg 1, was analysed and it was shown that a large reduction of package stresses without losing sensitivity for the pressure is theoretically possible For devices of which the

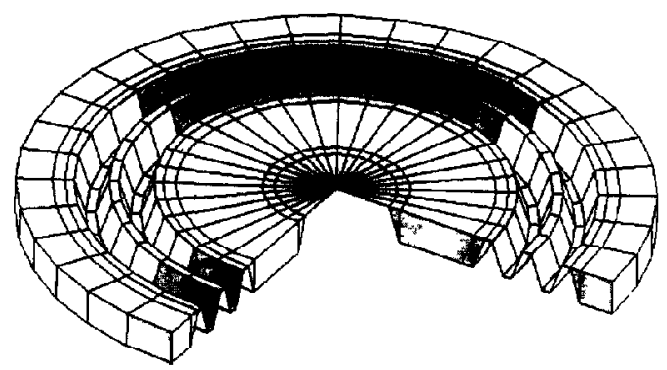

Fig 1 The bare structure a thin membrane surrounded by a thick rim and a thin corrugated decoupling zone integration of zone technology and sensor technology is possible it is attractive to fabricate the zone on-chip For complex sensors the zone could be fabricated separately in a wafer and then bonded to the sensor chip as a support chip [3] Note that in the case of an on-chip zone, electrical connections will have to pass this zone, while in case of the off-chip zone, the requirement of electrical connections across the zone is avoided In this paper the fabrication process of the bare structure, $1 \mathrm{e}$, a decoupling zone without electrical connections, is described

The fabrication process of the bare structure without electrical connections consists basically of three steps, see Fig 2 (1) frontside etching of deep curcular grooves in a silicon wafer, (2) deposition or growth of an etch stop layer on the front side, and (3) backside etching of the silicon wafer

For the on-chip application step (3) could be combined with a possible backside etchung step of the device itself, e $g$, to realize the membrane in $F_{1 g} 1$ Several methods and materials are possible for each step and result in then zones of different shape and material

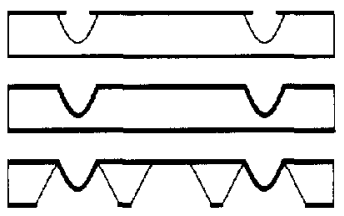

(1)

(2)

(3)

Fig 2 The fabrication process of the bare structure in steps 
Front side etching of deep circular grooves in a silicon wafer

This paper focuses on the first step of the fabrication process the front side etching of deep curcular grooves The exact demands of the geometry of the groove and hence the decoupling zone, like the cross-sectional shape, depth and position of the zone, depend on the application In ref 2 a design rule is given for the stress reduction of a V-shaped zone as a function of its geometry This rule gives an indication of the needed depth of a corrugated zone for a certain reduction $A$ typical value for the depth of a zone with a reduction of 2 or 3 orders is of magnitude $150 \mu \mathrm{m}$ Steep sidewalls of the zone are desirable for efficient use of chip area, but vertical sidewalls may cause problems if, later in the process, electrical connections have to be deposited in the groove Sharp corners will lead to stress concentration [4] so the ideal shape of the cross section will be a $\mathrm{V}$ with rounded bottom point and rounded edges The anisotropy of the etching process of the groove will affect the steepness of the walls Therefore an etch process with controllable anisotropy will be attractive

Wet-isotropic etching with a $\mathrm{HNO}_{3} / \mathrm{HF} / \mathrm{H}_{2} \mathrm{O}$ solution as well as reactive ion etching (RIE) with a sulphurhexafluoride/oxygen $\mathrm{SF}_{6} / \mathrm{O}_{2}$ plasma are investigated By varying the ratio between the chemical and physical contribution of the RIE process the underetch can be varied

\section{Wet etching in a $\mathrm{HNO}_{3} / \mathrm{HF} / \mathrm{H}_{2} \mathrm{O}$ solution}

The etching of silicon in a $\mathrm{HNO}_{3} / \mathrm{HF} / \mathrm{H}_{2} \mathrm{O}$ solution proceeds by a sequential oxidation-followed-by-dissolution process [5] In those composition regions where the solution is very low in $\mathrm{HNO}_{3}$ and nich in $\mathrm{HF}$, the rate-limiting process is the oxidation step In those compositions where $H F$ is in limited supply, dissolution of the formed oxide is the rate-controlling step, and makes diffusion of fluonde the important factor Therefore the hydrodynamic control, like stirring, has its consequences on the etch process Schwartz and Robbins [5] characterized several regions in the $\mathrm{HNO}_{3} / \mathrm{HF} /$ $\mathrm{H}_{2} \mathrm{O}$ composition plane by etch rate as well as the resulting geometry like the shape of corners and edges or the roughness of the etched surface

The wafers were etched horizontally in a $400 \mathrm{ml}$ Teflon beaker with the etched surface upside The amount of solution was $150 \mathrm{ml}$ and it was magnetically stırred at $50 \mathrm{rpm}$ at a temperature of $20^{\circ} \mathrm{C} \mathrm{A} 05 \mu \mathrm{m}$ thick silicon nitride mask was used with process specifications $\mathrm{SiCl}_{2} \mathrm{H}_{2} \mathrm{NH}_{3}=7018 \mathrm{sccm}, P=27 \mathrm{~Pa}$, $T=850{ }^{\circ} \mathrm{C}$ The etch area in the mask is about $1 \%$ of a $3^{\prime \prime}$ p-silicon wafer The process that met the needs of our requirements was process $\mathrm{I}(70 \%) \mathrm{HNO}_{3}(50 \%) \mathrm{HF}$ $\mathrm{H}_{2} \mathrm{O}=56737 \mathrm{w} / \mathrm{o}, 150 \mathrm{ml}$, stırring $50 \mathrm{rpm}$, horizon-

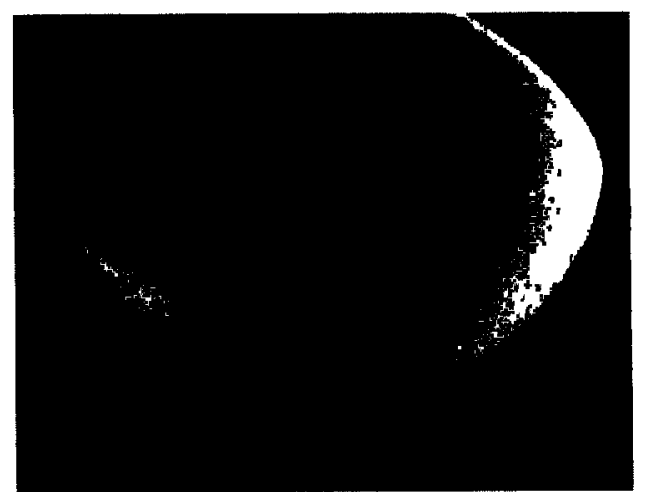

Fig 3 SEM photograph of a cross section of a circular groove etched in the $\mathrm{HNO}_{3} / \mathrm{HF} / \mathrm{H}_{2} \mathrm{O}$ solution of process I

tally, $20^{\circ} \mathrm{C}$, etch time $90 \mathrm{mun}$, mask $05 \mu \mathrm{m}$ LPCVD silicon nitnde

For the solution mentioned above the etch selectivity silicon/nitride amounted to 500/1 Figure 3 shows a SEM photograph of the cross section of a groove etched by process I A specular groove with a depth of $145 \mu \mathrm{m}$ accompanied by an underetch of $145 \mu \mathrm{m}$ is the result the etch process is isotropic Repeating of this experiment and experiments with compositions close to the $56737 \mathrm{w} / \mathrm{o}$ demonstrated that the values of etch rate and selectivity vary within $10 \%$ For each exper1ment fresh solutions were made because evaporation had changed the solution composition

\section{Reactive ion etching with $\mathrm{SF}_{6} / \mathrm{O}_{2}$}

RIE is a dry-etch technique which requires a plasma The etch process has a chemical (1sotropic) and a physical contribution, the latter caused by a $d c$ bias voltage that accelerates positive ions into the direction of the sample The etch result (etch rate, selectivity, anisotropy) depends on the electrode configuration, the plasma parameters (gas, gas flow, pressure), the $r f$ parameters (power, frequency and $\mathrm{d} c$ bias), the temperature and the sample (mask material, etch material, etch area)

The reactor used in this study was a parallel plateelectrode configuration of the type Plasmafab 340 The lower electrode with an area of $240 \mathrm{~cm}^{2}$ was powered by a $1356 \mathrm{MHz}$ RF generator The powered electrode was fahricated of titanium-coated alumınium and it was water-cooled at $25^{\circ} \mathrm{C} \mathrm{A} \mathrm{SF}_{6} / \mathrm{O}_{2}$ plasma was used $\mathrm{SF}_{6}$ is known to have an isotropical etch behaviour and usually this plasma is applicd for decp ctching in silicon when a large undercut, or even a total undercut to etch free-standing structures, is required [6, 7] However, we will show that under certain conditions of a $\mathrm{SF}_{6} / \mathrm{O}_{2}$ plasma it is possible to decrease the underetch To avord the loading effect, $1 \mathrm{e}$, a decrease in the concen- 
tration of reactive particles (F), the (maximum) flow rate of $12 \mathrm{sccm} \mathrm{SF}_{6}$ was used, and the etch area was kept as small as possible (only one wafer at the same time in the etch chamber) To increase the etch rate $3 \mathrm{sccm} \mathrm{O}_{2}$ was added At this $20 \mathrm{vol} \% \mathrm{O}_{2}$ addition a maximum etch rate was detected, which is in agreement with literature [8]

An aluminum mask was appled and the resist used for the patterning of the mask was stripped before etching to prevent contamunation by radicals containing carbon Due to the absence of carbon (C) and the existence of oxygen $\left(\mathrm{O}_{2}\right)$ the generation of polymers (some times resulting in nearly vertical walls) is prevented and it is expected that a clean surface will result $[8,9]$ Note that the addition of $\mathrm{O}_{2}$ can reduce the redeposition of aluminum $[6-8]$ the $\mathrm{O}_{2}$ seems to form alumina out of the aluminum, which is resistant in fluonne plasmas

Two processes will be discussed, both carried out with $123 \mathrm{sccm} \mathrm{SF}_{6} \mathrm{O}_{2}$ at $25^{\circ} \mathrm{C}$

Process II $27 \mathrm{~Pa}, 80 \mathrm{~W}$, dc bras $525 \mathrm{~V}$, etch tume $60 \mathrm{mun}$, mask $05 \mu \mathrm{m} \mathrm{SiO}_{2}+02 \mu \mathrm{m}$ aluminum,

Process III $16 \mathrm{~Pa}, 50 \mathrm{~W}$, dc bras $32 \mathrm{~V}$, etch tame $30 \mathrm{~mm}$, mask $05 \mu \mathrm{m}$ alummum

In process II (low pressure, high power) the aluminum mask is easily degenerated Tenslle stress bult up in the layer during etching caused the inner overhang of the mask to deform to a polygonal shape The solution of this problem was found in growing a slicon dioxide layer before the evaporation of aluminum The tensile stress in the alummum due to the ion bombardment will not be large enough to compensate the compressive stress in the oxide layer Thus bilayer mask resulted after etching in an overhang with a periodic corrugation, which has been observed by other authors for a rectangular stlicon dioxide overhang $[10,11]$ Compressive forces in the silicon dioxide reduce the stiffness of the layer, resulting in a singulanty comparable with the buckling of a beam under compression These deformations manifest only in the vertical direction, which means that the projection of the mask on the bottom remains circular, so for this purpose application is possible

Figure 4(a) shows a SEM photograph of the groove after etching with process II ( $27 \mathrm{~Pa}, 80 \mathrm{~W})$ With a mask opening of $50 \mu \mathrm{m}$, an etch depth of $140 \mu \mathrm{m}$ was accompanied by an underetch of $130 \mu \mathrm{m}$ after $60 \mathrm{~mm}$ etching This relatively large underetch region points to an almost isotropic etch process The cross section of this groove is characterized by a smooth bottom but very rough sidewalls The roughness of the sidewalls could be caused by redeposited particles (contamination) which are not easily sputtered away like particles on the bottom

In process III (high pressure, low power) the aluminium mask was suffictent At this lower $\mathrm{d} c$ bias

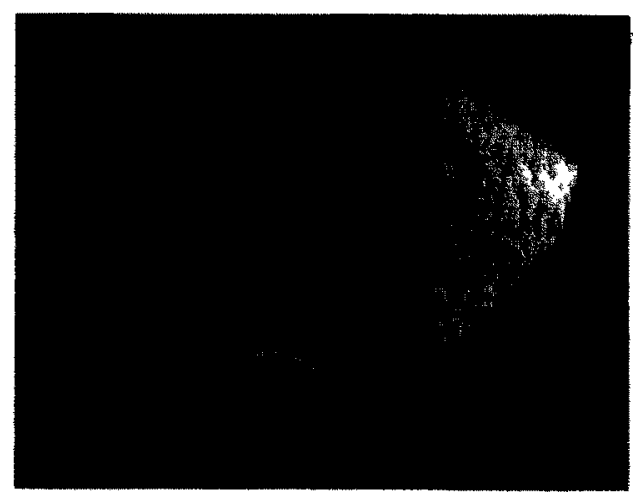

(a)

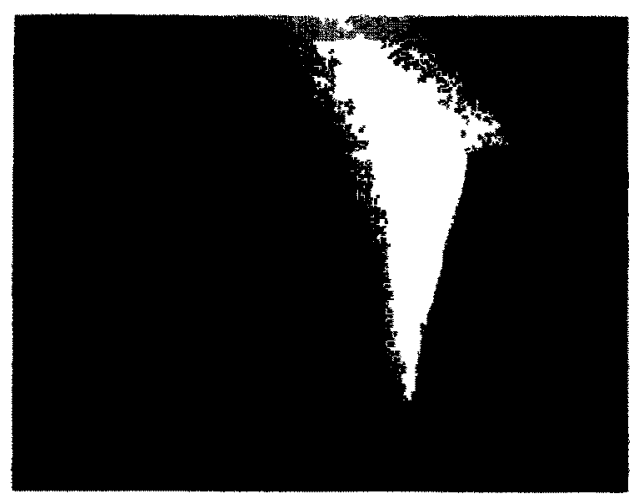

(b)

Fig 4 SEM photographs of cross sectrons of RIE etched grooves (a) process II with $27 \mathrm{~Pa}$ and $80 \mathrm{~W}$ after $60 \mathrm{mn}$, and (b) process III with $16 \mathrm{~Pa}$ and $50 \mathrm{~W}$ after $30 \mathrm{~min}$

voltage the mask was not deformed and kept its ongnal shape, which agrees with the assumption that the physical impact causes the mask deformation It also indicates that eventually residual stress in the alumunum layer, caused by the evaporation process, is not sufficient to deform the overhang

Figure 4(b) shows a SEM photograph of a groove etched with process III (16 Pa, 50 W) After $30 \mathrm{~mm}$ etching the depth of the groove was $110 \mu \mathrm{m}$, accompanied by an underetch of $30 \mu \mathrm{m}$ The increase of the vertical etch rate from 23 to $37 \mu \mathrm{m}$ per min at this process compared with process II mdicates that the chemical contribution in the etch process is dominating This was expected after the isotropic etch result of process II However the groove etched by process III has smooth steep sidewalls with a slope of 37 The large decrease of undercut at this higher pressure and lower $\mathrm{d} c$ bias voltage is remarkable A possible explanation is that products from the etchung process react on the slicon surface and produce a thin film At the bottom this layer is removed by physical sputtering but 
TABLE 1 Characterization of the etch results of deep etching in slicon by wet etching (process I) and by dry etching at low and high pressure (process II, III)

\begin{tabular}{|c|c|c|c|}
\hline \multirow[t]{2}{*}{ Characterization } & \multicolumn{3}{|l|}{ Etch process } \\
\hline & $\begin{array}{l}\text { I } \\
\text { (wet isotropic) }\end{array}$ & $\begin{array}{l}\text { UI } \\
\text { (RIE, } 27 \mathrm{~Pa})\end{array}$ & $\begin{array}{l}\text { III } \\
(\mathrm{RIE}, 16 \mathrm{~Pa})\end{array}$ \\
\hline Etch time (min) & 90 & 60 & 30 \\
\hline Depth $(\mu \mathrm{m})$ & 145 & 140 & 110 \\
\hline Underetch ( $\mu \mathrm{m})$ & 145 & 130 & 30 \\
\hline Shape sidewalls & rounded & rounded & oblique \\
\hline Roughness sidewalls & very smooth & very rough & smooth \\
\hline Shape bottom & round & round & flat, rounded edges \\
\hline Roughness bottom & very smooth & smooth & rough \\
\hline Mask selectıvity & 5001 & $130(05+02)$ & $>5001$ \\
\hline
\end{tabular}

at the sidewalls the film protects the silicon from further etching This gives also an explanation for the smoothness of the walls compared with the rough sidewalls obtained at the lower pressure RIE process The thin film seems to be produced at a certain level of chemical etching This result shows that it is possible with an $\mathrm{SF}_{6} / \mathrm{O}_{2}$ plasma to obtain an anisotropic geometry for deep grooves To understand the exact mechanism further research at various pressures and powers will be done, as well as the characterization of the chemical composition of the sidewalls

\section{Polishing}

The roughness of the surface can be reduced if the etch process is followed by a polishing process after stripping the mask, the upper surface is uniformly etched An 1sotropic etch process will have good polishing qualities for rough surfaces and therefore the $\mathrm{HNO}_{3} / \mathrm{HF} / \mathrm{H}_{2} \mathrm{O}$ solution was first applied for this goal But at etching large silicon surfaces in this solution the production of hydrogen plays a role Produced bubbles lead to craters in the surface of horzontally-placed wafers and to stripes for vertically-placed wafers In the last case the bubbles move upwards across the surface The solution here is to apply a dry-polishing etch method like RIE with $\mathrm{SF}_{6}$ under chemical conditions

Comparison of method for etching deep grooves in silicon Results of circular grooves etched by the $\mathrm{HNO}_{3} / \mathrm{HF} /$ $\mathrm{H}_{2} \mathrm{O}$ solution and two RIE processes, at lower and higher pressure, are compared and given in Table 1 The summary descriptions of the etch processes are Process I $\mathrm{HNO}_{3} \mathrm{H}_{2} \mathrm{O}=56737 \mathrm{w} / \mathrm{o}, 150 \mathrm{ml}$, sturred at $50 \mathrm{rpm}$,

Process II low pressure RIE (2 $7 \mathrm{~Pa}, 80 \mathrm{~W})$, and

Process III high pressure RIE ( $16 \mathrm{~Pa}, 50 \mathrm{~W}$ )

Depending on the application and requirements one of these etch processes can be used The wet-isotropic process I gives very smooth surfaces but a large under- etch To require steep walls and a small undercut RIE process III should be applied RIE process II gives a geometry with large underetch, comparable to process I, but results in very rough sidewalls The roughness can be reduced if the etch process is followed by a dry-etch polish process

\section{Step 2 and step 3: etch stop layer at the frontside and backside etching}

After etching the deep grooves, removing the mask, and possibly polishing the surface, the layer deposition step 2 and the backside etching step 3 is done, see also Fig 2 Several matenals and methods are possible for these steps In general, for step 2 any material with a sufficient selectivity for the etch method in step 3 can be applied Especially for an on-chip fabricated zone the choice should fit in the sensor realization process $A$ silicon nitride decoupling zone is presented as an example here

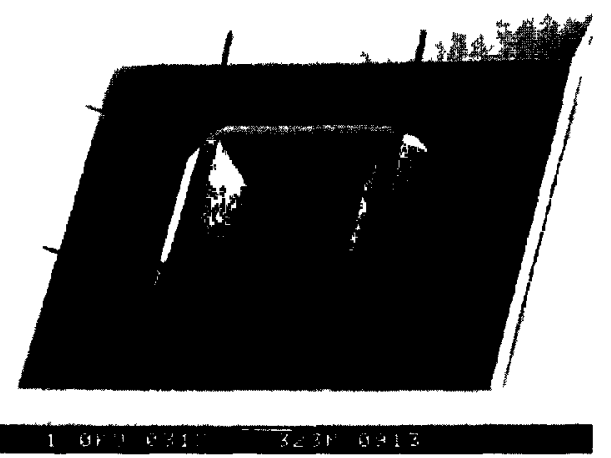

Fig 5 SEM photograph from the backside of a square silicon nitride membrane surrounded by a decoupling zone with a circular groove 
Figure 5 shows a SEM photograph from the backside of a square silicon nitride membrane, suspended by a thick square rim, surrounded by a thin rectangular area containing a circular decoupling zone with a depth of $100 \mu \mathrm{m}$ The grooves were etched by RIE (process II) and covered with $1 \mu \mathrm{m}$ LPCVD silicon nitnde The backside etching was done with a $\mathrm{KOH}$ solution $(25 \%$, $72{ }^{\circ} \mathrm{C}$ ) A mask correction was applied to limit the underetch at the convex corners of the thick rim At the convex corners two perpendicular beams with $1100 \mu \mathrm{m}$ length and $50 \mu \mathrm{m}$ width were added in the mask The beams in the nitnde backside mask as well as the resultıng oblique walls at the convex corners are clearly visible in the SEM photograph

\section{Conclusions}

The fabrication of mechanical decoupling zones around a membrane to reduce package stresses is presented A deep circular groove is necessary for this application and a wet isotropic etch method with a $\mathrm{HNO}_{3} / \mathrm{HF} / \mathrm{H}_{2} \mathrm{O}$ solution as well as reactive ion etching (RIE) with a sulphurhexafluonde/oxygen $\mathrm{SF}_{6} / \mathrm{O}_{2}$ plasma are compared The wet isotropic method results in a groove with a smooth surface and a relatively large undercut The selectivity of the LPCVD silicon nitride mask to sllicon was 1 to 500 With the RIE method, the shape of the cross section of the groove can be controlled by changing the etch conditions For low pressure isotropic behaviour was found, as expected for a plasma containing fluorine atoms However, for higher pressures the undercut was much smaller while the side walls were smooth and oblique, probably due to the formation of a fluorine-resistive layer at the side walls The bottom of the groove is relatively smooth and flat with rounded edges This result meets the requrements for application as an on-chip decoupling zone Finally, a complete structure containing a membrane and a surrounding decoupling zone is realized

\section{References}

1 S D Senturia and R L Smith, Microsensor packaging and system partitioning, Sensors and Actuators, 15(1988) 221-234

2 V L Spiering, S Bouwstra, $R$ M E J Spiening and M Elwenspoek, On-chip decouplung zone for package-stress reduction, Proc 6ith Int Conf Sold-State Sensors and Actuators (Transducers '91), San Francisco, CA, USA, June 24-27, 1991, pp 982-985

3 H L Offereins and H Sandmaier, Novel stress free assembly technique for micromechanical devices, Proc Micro System Technologies 90, Berlin, Germany, Sept 10-13, 1990, pp 515520

4 F Pourahmadi, D Gee and K Petersen, The effect of corner radius of curvature on the mechanical strength of micromachined single-crystal silicon structures, Proc 6th Int Conf Sold-State Sensors and Actuators (Transducers '91), San Francisco, CA, USA, June 24-27, 1991, pp 197-200

5 B Schwartz and $\mathrm{H}$ Robbuns, Chemical etching of sihcon IV Etching technology, J Electrochem Soc, 123 (1976) 19031909

$6 \mathrm{C}$ Linder, $\mathrm{T}$ Tschan and N F de Rooy, Deep dry etching techniques as a new IC compatible tool for slicon micromachining, Proc 6th Int Conf Solid-State Sensors and Actuators (Transducers '91), San Francisco, CA, USA, June 24-27, 1991, pp 524-527

7 T Tschan, C Linder and N F de Rooly, Dry etching techniques for silicon micromachining, Tech Dig MME '90, 2nd Workshop on Micromachining, Micromechanics and Microsystems, Berlm, Germany, Nov 26-27, 1990

8 R Pinto, K V Ramanatham and R S Babu, Reactive ion etching in $\mathrm{SF}_{6}$ gas mixtures, $J$ Electrochem $S o c, 134$ (1987) $165-175$

$9 \mathrm{~K} \mathrm{M}$ Elsele, $\mathrm{SF}_{6}$, a preferable etchant for plasma etchung silicon, $I$ Electrochem Soc, 128 (1981) 123-126

10 S C H Lin and I Pugacz-Muraskiewicz, Local stress measurement in thin thermal $\mathrm{S}_{2} \mathrm{O}_{2}$ films on $\mathrm{S} 1$ substrates, $J$ Appl Phys, 43 (1972) 119-125

$11 \mathrm{P} G$ Borden, A simple technique for determining the stress at the $\mathrm{S} / \mathrm{S}_{1} \mathrm{O}_{2}$ interface, Appl Phys Lett, $36(1980)$ 829-831 